Published in final edited form as:

Dent Mater. 2009 December ; 25(12): 1569-1575. doi:10.1016/j.dental.2009.07.010.

\title{
Water sorption and dynamic mechanical properties of dentin adhesives with a urethane-based multifunctional methacrylate monomer
}

\author{
Jong-Gu Park ${ }^{\mathrm{a}}$, Qiang Ye ${ }^{\mathrm{a}}$, Elizabeth M. Topp ${ }^{\mathrm{b}}$, Anil Misrac ${ }^{\mathrm{C}}$, and Paulette Spencer ${ }^{\mathrm{a}, \mathrm{d}}{ }^{\text {* }}$ \\ aBioengineering Research Center, School of Engineering, University of Kansas, Lawrence, Kansas, \\ USA \\ bDepartment of Pharmaceutical Chemistry, School of Pharmacy, University of Kansas, Lawrence, \\ Kansas, USA \\ 'Department of Civil, Environmental and Architectural Engineering, University of Kansas, Lawrence, \\ KS, USA \\ ${ }^{\mathrm{d} D e p a r t m e n t}$ of Mechanical Engineering, University of Kansas, Lawrence, Kansas, USA
}

\begin{abstract}
Objectives-Our previous study showed the synthesis and characterization of a novel urethanelinked trimethacrylate monomer for use as a co-monomer in dentin adhesives. The objective of this work was to further investigate the performance of dentin adhesives containing a new monomer, with particular emphasis on the water sorption and visco-elastic behavior of the crosslinked networks.

Materials and methods-Dentin adhesives contained 2,2-bis[4-(2-hydroxy-3methacryloxypropoxy) phenyl]-propane (BisGMA), 2-hydroxyethyl methacrylate (HEMA), and a new multifunctional methacrylate with urethane-linked groups-1,1,1-tri-[4(methacryloxyethylaminocarbonyloxy)-phenyl]ethane (MPE) and were photo-polymerized in the presence or absence of water. Adhesives were characterized with regard to degree of conversion (DC), viscosity, water sorption/solubility, and via dynamic mechanical analysis (DMA) and compared with BisGMA/HEMA controls.
\end{abstract}

Results-The experimental adhesives exhibited DC and solubility comparable to that of the control, regardless of the presence or absence of water. All the experimental adhesives tested showed less water sorption, lower $\tan \delta$ peak heights, and higher rubbery modulus than the control.

Significance-Dentin adhesives containing a new multifunctional methacrylate showed better dynamic thermomechanical properties and water sorption relative to controls, without compromising DC and solubility. Thus, MPE, when included as a component of methacrylate dentin adhesives, may provide enhanced durability in the moist environment of the mouth.

(C) 2004 Academy of Dental Materials. Published by Elsevier Ltd. All rights reserved.

*Address all correspondence to Dr. Paulette Spencer. Tel.: +1 785864 8140; fax: 1785864 1742; pspencer@ku.edu.

Publisher's Disclaimer: This is a PDF file of an unedited manuscript that has been accepted for publication. As a service to our customers we are providing this early version of the manuscript. The manuscript will undergo copyediting, typesetting, and review of the resulting proof before it is published in its final citable form. Please note that during the production process errors may be discovered which could affect the content, and all legal disclaimers that apply to the journal pertain. 


\section{Keywords}

dentin adhesives; water sorption; dynamic mechanical analysis; multifunctional methacrylate; storage modulus; crosslink density; tan delta; degree of conversion

\section{Introduction}

The mechanical properties of dentin adhesives are critical to their long-term performance in the mouth. Traditionally, the mechanical properties of dental materials have been investigated using static tests. However these methods are not always well suited for measuring the complete material deformation and stiffness properties. This is particularly true for materials which show viscoelastic behaviour under load [1]. Since dental restorative materials are subjected to dynamic loading rather than static loading in the mouth, dynamic tests have become increasingly relevant [2]. Dynamic methods are often preferred [3] as they better mimic the cyclic masticatory loading to which these materials are subjected clinically.

Water present in the mouth is a major interfering factor when bonding adhesives and/or composites to the tooth [4]. The water content of the dentin surface varies as a function of depth [5], the nature of the substrate (i.e. caries-affected or healthy) [6], and the presence of residual rinse water. Under in vivo conditions, there is little control over the amount of water left on the tooth during dentin bonding. In addition to being subject to masticatory stresses, dental materials absorb water in the oral cavity, compromising their physical and mechanical properties, accelerating the degradation of the material, softening of dental resins through plasticization, and facilitating the release of unreacted monomers and degradation products $[4,7,8]$. The study of water sorption and solubility of dental materials is important to understand their long-term performance, since water may promote a variety of chemical and physical processes that create biological concerns as well as producing deleterious effects on the structure and function of the polymer matrix itself.

The selection of the monomers used in dentin adhesives has a considerable influence on the reactivity, degree of conversion, mechanical properties and water uptake of the final materials. In our previous work, we reported the synthesis and characterization of a novel urethane-linked trimethacrylate monomer for use a co-monomer in dentin adhesives and evaluated its physical and mechanical properties to gain perspective on its potential use as a co-monomer in dentin adhesives [9]. The studies presented here further investigate the performance of adhesives containing this new monomer, with particular emphasis on the water sorption and visco-elastic behavior of the crosslinked networks under a simulated wet oral environment. Thus, the objective of this work was to evaluate the water sorption and dynamic mechanical properties of dentin adhesives formulated with the newly synthesized urethane-based multifunctional methacrylate monomer.

\section{Materials and methods}

\subsection{Materials}

2,2-bis[4-(2-hydroxy-3-methacryloxypropoxy) phenyl]-propane (BisGMA, Polysciences, Warrington, PA) and 2-hydroxyethylmethacrylate (HEMA, Acros Organics, NJ) were used as received without further purification as monomers in dentin adhesives. 1,1,1-tri-[4(methacryloxyethylaminocarbonyloxy)-phenyl]ethane (MPE) has been recently synthesized in our laboratories [9] and was used as a co-monomer. The control adhesive resin was composed of BisGMA and HEMA with a mass ratio of 55/45 and formulated with $0 \mathrm{wt} \%$ (C0), $8 \mathrm{wt} \%$ (C8) and $16 \mathrm{wt} \%$ (C16) water to simulate wet bonding in the mouth. This control was compared to experimental adhesive resins, BisGMA/HEMA/MPE $=30 / 45 / 25 \mathrm{w} / \mathrm{w}$ ratio, which were also 
formulated with $0 \mathrm{wt} \%$ (E0), $8 \mathrm{wt} \%$ (E8) and $16 \mathrm{wt} \%$ (E16) water. The water concentration values $(0,8$ and $16 \mathrm{wt} \%)$ were selected on the basis of our previous work [10-12]. The concentration of water was based on the total final weight of the adhesive resin. In this study, heavy water (deuterium oxide, $\left.99.9 \%, \mathrm{D}_{2} \mathrm{O}\right)($ Cambridge Isotope Laboratories, Inc. Andover, MA, USA) was used due to the absence of an overlapping water peak at $1640 \mathrm{~cm}^{-1}$, where monitoring of the aliphatic $\mathrm{C}=\mathrm{C}$ bond is essential for determining degree of conversion. Camphorquinone (CQ) and ethyl-4-(dimethylamino)benzoate (EDMAB) were obtained from Aldrich (Milwaukee, WI, USA) and used as a photoinitiator system without further purification. 1,1,1-tris(4-hydroxyphenyl)ethane, dibutyltin dilaurate (DBTL), and 2isocyantoethyl methacrylate (IEM) were obtained from Aldrich, Milwaukee, WI, USA and used for MPE synthesis. All other chemicals were reagent grade and used without further purification.

\subsection{Viscosity measurement}

Viscosities of the adhesive resins were measured with a TA Instruments AR2000 rheometer (New Castle, Delaware, US) in the controlled-rate mode. The measurements were made at 25 ${ }^{\circ} \mathrm{C}$ with $40 \mathrm{~mm}$ diameter and $2{ }^{\circ}$ cone angle in the shear rate range of $10 / \mathrm{s}$ to $100 / \mathrm{s}$, at 10 points per decade. At each shear rate, shear was applied for 60 seconds before the viscosity measurement, which was collected in the last 10-second sample period. The ten viscosity measurements over the shear rate range were averaged.

\subsection{Specimen preparation}

Rectangular beam specimens $\left(1 \times 1 \times 15 \mathrm{~mm}^{3}\right)$ were made by curing the resin in a glass-tubing mold (Wilmad Labglass, \#LG-25001-100, Standard wall borosilicate tubing) and used for the determination of water sorption and solubility, degree of conversion (DC) and dynamic mechanical properties. The adhesive resins were light-cured for $40 \mathrm{sec}$ at room temperature with a LED light curing unit (LED Curebox, Proto-tech, Portland, OR, USA). The polymerized samples were stored at room temperature for 2 days in a dark room, and then for 1 week in a vacuum oven in the presence of a drying agent at $37^{\circ} \mathrm{C}$.

\subsection{Degree of conversion (DC)}

The DC was determined by using a LabRAM ARAMIS Raman spectrometer (LabRAM HORIBA Jobin Yvon, Edison, New Jersey) with a HeNe laser ( $\lambda=633 \mathrm{~nm}$, a laser power of 17 $\mathrm{mW})$ as an excitation source [13,14]. The instrument conditions were: $200 \mu \mathrm{m}$ confocal hole, $150 \mu \mathrm{m}$ wide entrance slit, $600 \mathrm{gr} / \mathrm{mm}$ grating, and $10 \times$ objective Olympus lens. Data processing was performed using LabSPEC 5 (HORIBA Jobin Yvon). The samples were mounted in a computer-controlled, high-precision x-y stage. To determine the DC, spectra of the uncured resins and beam samples were acquired over a range of $700-1800 \mathrm{~cm}^{-1}$. The change of the band height ratios of the aliphatic carbon-to-carbon double bond $(\mathrm{C}=\mathrm{C})$ peak at $1640 \mathrm{~cm}^{-1}$ and the aromatic $\mathrm{C}=\mathrm{C}$ at $1610 \mathrm{~cm}^{-1}$ (phenyl) in both the cured and uncured states was monitored and the DC calculated using the following equation based on the decrease in the intensity band ratios before and after light curing.

$$
\mathrm{DC}(\%)=\left[1-\left(\mathrm{R}_{\text {cured }} / \mathrm{R}_{\text {uncured }}\right)\right] \times 100,
$$

where $\mathrm{R}=$ band height at $1640 \mathrm{~cm}^{-1} / \mathrm{band}$ height at $1610 \mathrm{~cm}^{-1}$. The average was obtained from four readings. 


\subsection{Water sorption and solubility}

Water sorption and solubility were measured using rectangular beam specimens $(1 \times 1 \times 15$ $\mathrm{mm}^{3}$ ) made exactly as those used for dynamic mechanical analysis (DMA). Four specimens were prepared for each dentin adhesive. The polymerized samples were stored at room temperature for 2 days in a dark room, and then for 1 week in a vacuum oven in the presence of a freshly dried silica gel at $37{ }^{\circ} \mathrm{C}$. Samples were then stored in a desiccator at $23{ }^{\circ} \mathrm{C}$ for $1 \mathrm{~h}$ and weighed with a calibrated electronic balance (a resolution of $0.01 \mathrm{mg}$ ). This drying cycle was repeated until a constant mass $\left(m_{1}\right)$ for each specimen was obtained. After drying, the specimens were immersed in distilled water at $37^{\circ} \mathrm{C}$. At fixed time intervals $(3 \mathrm{~h}, 5 \mathrm{~h}, 24 \mathrm{~h}, 2 \mathrm{~d}$, $4 \mathrm{~d}, 7 \mathrm{~d}, 10 \mathrm{~d})$ they were removed, blotted to remove excess water, weighed $\left(m_{2}\right)$ and returned to the water until a constant weight was obtained. All the specimens were then removed from the water and placed in a vacuum oven containing a freshly dried silica gel at $37^{\circ} \mathrm{C}$ until a constant weight was achieved $\left(m_{3}\right)[8,15]$. The values $(\%)$ for water sorption $\left(W_{s p}\right)$ and solubility $\left(W_{s u}\right)$ were calculated as

$$
\begin{aligned}
& W_{\mathrm{sp}}(\%)=\left(m_{2}-m_{1}\right) / m_{1} \\
& W_{\mathrm{su}}(\%)=\left(m_{1}-m_{3}\right) / m_{1}
\end{aligned}
$$

\subsection{Dynamic mechanical analysis (DMA)}

The viscoelastic properties of the dentin adhesives were characterized using DMA Q800 (TA Instruments, New Castle, USA) with a three-point bending clamp. Rectangular beam specimens $\left(1 \times 1 \times 15 \mathrm{~mm}^{3}\right)$ were divided into two groups of total six samples each. The first group consisted of dry samples, which had been stored in the dark at room temperature for 2 days and for 1 week in a vacuum oven in the presence of a freshly dried silica gel at $37^{\circ} \mathrm{C}$. These specimens were tested by standard 3-point bending clamp (Fig. 1a). The test temperature was varied from 0 to $200{ }^{\circ} \mathrm{C}$ with a ramping rate of $3{ }^{\circ} \mathrm{C} / \mathrm{min}$ at a frequency of $1 \mathrm{~Hz}$.

The second group consisted of wet samples, which had been dried as above and stored in distilled water at $37^{\circ} \mathrm{C}$ for 5 days and then tested by 3 -point bending using a water-submersion clamp (Fig. 1b). The test temperature was varied from 4 to $80^{\circ} \mathrm{C}$ with a ramping rate of $3{ }^{\circ} \mathrm{C} /$ min at a frequency of $1 \mathrm{~Hz}$. The properties measured under this oscillating loading are storage modulus (E') and $\tan \delta$. The E' value represents the stiffness of a viscoelastic material and is proportional to the energy stored during a loading cycle. The ratio of loss modulus (E") to storage modulus E' is referred to as the mechanical damping, or $\tan \delta$ (i.e., $\tan \delta=\mathrm{E}^{\prime}$ / E'). The $\tan \delta$ value reaches a maximum as the polymer undergoes the transition from the glassy to the rubbery state. The glass transition temperature $(\mathrm{Tg})$ was determined as the position of the maximum on the $\tan \delta$ vs. temperature plot. Five specimens of each material were measured and the results averaged.

The results were analyzed statistically using analysis of variance (ANOVA), together with Tukey's test at $\alpha=0.05$ (Microcal Origin Version 6.0, Microcal Software Inc., Northampton, MA).

\section{Results}

The viscosities of adhesive resins containing different water content are shown in Table 1 . The viscosity decreased in the order (mPa $\bullet$ ): E0 (234) > C0 (191) > E8 (110) > E16 (83) > C8 (79) $>$ C16 (65). Table 1 also shows the degree of conversion of the adhesive polymers. The DC for samples cured in the absence of water was $\sim 91 \%$, while samples cured in the presence of water showed a somewhat higher DC ( 96\%). 
In distilled water at $37^{\circ} \mathrm{C}$, the control and experimental adhesives showed water sorption behavior (Fig. 2, Table 2). All the samples tested exhibited rapid water sorption in the first 24 $\mathrm{h}$ of immersion in distilled water. The time required to reach maximum water sorption was greatest in polymer $\mathrm{C} 16$ and E16. The water solubility varied from a low of $0.5 \%$ for $\mathrm{C} 0$ and E0 to a high of $1.6 \%$ for C16 (Table 2). Since water sorption and solubility occur simultaneously, they were added together to provide an estimate of the total water uptake. These values varied from $9.4 \%$ to $16.9 \%$ (Table 2).

Fig. 3 shows representative tan delta curves of control and experimental adhesive polymers as a function of temperature. The heights of the tan delta peaks and corresponding full-width-athalf-maximum values are given in Table 3. All samples showed a wide range of widths of the $\tan \delta$ curves; overall, the $\tan \delta$ peak heights of experimental adhesives were significantly lower $(\mathrm{p}<0.05)$ than those of control. Tg values for $\mathrm{C} 0$ and $\mathrm{E} 0$ were nearly identical, but the differences in Tg between the control and experimental adhesives cured in the presence of water were significant $(\mathrm{p}<0.05)$.

Table 4 shows the values of average storage modulus ( $\mathrm{E}^{\prime}$ ) measured by standard 3-point bending clamp and by 3-point water-submersion clamp methods at various temperatures. For all samples, the storage moduli decreased slowly at low temperatures $\left(25,37^{\circ} \mathrm{C}\right)$. As the temperature was increased to the glass transition region $\left(\sim 145-165^{\circ} \mathrm{C}\right)$ the storage moduli decreased markedly. With continued heating, all samples reached the rubbery plateau region, in which there was no further decrease in storage modulus. In the rubbery region, the average storage moduli of experimental adhesives $(\sim 29-41 \mathrm{MPa})$ were significantly greater $(\mathrm{P}<0.05)$ than those of corresponding control adhesives ( 22-25 MPa). The average storage moduli (E ) measured using the 3-point water-submersion clamp method were significantly less than those of standard 3-point bending clamp. In addition, the storage moduli at $70{ }^{\circ} \mathrm{C}$ of experimental adhesives $(\sim 398-800 \mathrm{MPa})$ measured by using the submersion clamp method were significantly $(\mathrm{P}<0.05)$ greater than those of control samples $(\sim 261-454 \mathrm{MPa})$.

Fig. 4 shows the inverse ratio $(\zeta)$ of the modulus in the rubbery region to the temperature at which the modulus was measured, plotted as a function of water content (\%). The value of $\zeta$ is generally considered to be inversely correlated to the crosslink density of the network, with higher $\zeta$ values corresponding to lower crosslink density [16]. The experimental adhesives showed lower $\zeta$ values than those of the control adhesives regardless of water content. The lowest $\zeta$ values were observed for E8 and E16, suggesting that these samples have the highest crosslink density. This difference between control and experimental adhesives is greatest at the highest water content (16\%).

\section{Discussion}

Clinically, dentin adhesives are placed on the moist dentin surface and subsequently lightcured. Residual water on the dentin surface may dilute the adhesive monomers prior to polymerization, thereby influencing the formation of the polymer network and the resulting mechanical properties. Because of its small size, water is expected to penetrate into nano/ micrometer-size free volume spaces between polymer chains or cluster around functional groups that are capable of hydrogen bonding, which may alter mechanical properties observed at the macro scale. Water sorption initially causes a softening of the polymer network by swelling and reducing the frictional forces between the polymer chains. The absorbed water also acts as a plasticizer, lowering the mechanical properties of the polymer network [17]. Water sorption and solubility may also precede various chemical and physical processes that create biological concerns as well as producing structure/property changes in the polymer matrix. 
The results presented here showed no significant differences in the DC and solubility of control and experimental adhesive polymers, suggesting that the experimental adhesives reach DC and solubility comparable to that of the control, regardless of the presence or absence of water (Table 1 and Table 2). In addition, both control and experimental adhesives showed similar water sorption behavior. However, the experimental adhesives showed significantly $(\mathrm{P}<0.05)$ less water sorption, which may be due to greater crosslink density of the polymer network due to the higher functionality of the new monomer (Table 2). This result is also in agreement with previous investigations reporting that water sorption of dental polymers is affected by crosslinking $[18,19]$. The decreased water sorption of the experimental adhesives relative to controls is consistent with the DMA results, which showed higher crosslink density, and supports our previous report on the degradation of dentin adhesives [9].

Many dental materials contain crosslinked polymers formed by photopolymerization of multifunctional monomers and exhibit viscoelastic behavior when are exposed to cyclic masticatory loading in the oral environment [20]. Dynamic mechanical analysis (DMA) is particularly well suited to characterizing viscoelastic materials and has been suggested as a valuable tool for obtaining information regarding the crosslink density and structural heterogeneity of polymer networks, since the method measures both elastic and viscous responses [21,22]. In the current study, the widths of the $\tan \delta$ curves (Fig. 3,Table 3) indicate that the glass transition occurs over a wide temperature range. This broad glass transition can be attributed to heterogeneous networks containing both highly crosslinked and less densely crosslinked regions [22], resulting in a broad distribution of mobilities or relaxation times. The greater width for E0 (Table 3) is consistent with highly heterogeneous network regions, which may be due in part to restricted mobility of the propagating radicals in this solution of relatively high viscosity (Table 1 ). The intensity of the maximum $\tan \delta$ peak reflects the extent of mobility of the polymer chain segments at this temperature [23]. All experimental adhesives showed lower $\tan \delta$ peak heights than those of the control, indicating increasingly elastic behavior (i.e., more energy is stored in the material) and greater crosslink density[24,25]. The lower $\tan \delta$ peak heights in experimental adhesives may be due to greater crosslink densities in networks containing the new multifunctional monomer, MPE. The storage moduli of all the samples tested show a gradual decrease with increasing temperature, decreasing more drastically above $70{ }^{\circ} \mathrm{C}$ and finally reaching the rubbery plateau. The modulus value in the rubbery plateau has been related to the crosslink density of the material $[14,22,26]$. The ratio of rubbery modulus to the absolute temperature at which that modulus was measured, $\zeta$, is inversely related to the crosslinking density of polymer network [14,27]. By this measure, the adhesives formulated with newly synthesized monomer showed greater crosslink densities than those of control adhesives (Fig. 4). This is consistent with the results from water sorption and $\tan \delta$ data described above.

The 3-point bending water-submersion clamp method used in this study is expected to be representative of the wet environment of the mouth as compared to the standard 3-point bending clamp method. Samples can be heated to only $80^{\circ} \mathrm{C}$ for the 3-point bending water-submersion clamp method. The moduli of samples measured by the water-submersion clamp method were significantly less than those of dried samples measured by a standard clamp. This difference is likely due to plasticization $[4,7,28]$ of the polymer in the wet environment. The polar functional groups in the adhesive resins included hydroxyl groups in BisGMA and HEMA. Water attracted to polar groups in the polymer matrix forms hydrogen bonds resulting in reduced polymer chain interactions, e.g. entanglements and chemical bonding, and is responsible for plasticizing polymers. 


\section{Conclusions}

Water sorption and dynamic mechanical properties have been studied for new dentin adhesives containing a urethane-linked multifunctional methacrylate (MPE) and compared with a BisGMA/HEMA control. Experimental adhesives containing MPE showed less water sorption, lower $\tan \delta$ peak heights, and higher crosslink density than controls, without compromising DC. Thus, MPE, when included as a component of methacrylate dentin adhesives, may offer enhanced durability in the moist environment of the mouth.

\section{Acknowledgments}

This investigation was supported by Research Grant: R01DE14392 (PI: Spencer) from the National Institute of Dental and Craniofacial Research, National Institutes of Health, Bethesda, MD 20892.

\section{REFERENCES}

1. Whiting R, Jacobsen PH. Dynamic mechanical properties of resin-based filling materials. J Den Res 1980;59(1):55-60.

2. Yang J-M, Li H-M, Yang M-C, Shih C-H. Characterization of acrylic bone cement using dynamic mechanical analysis. J Biomed Mater Res Part B-Appl Biomater 1999;48:52-60.

3. Saber-Sheikh K, Clarke RL, Braden M. Viscoelastic properties of some soft lining materials: I-effect of temperature. Biomaterials 1999;20(9):817-822. [PubMed: 10226708]

4. Ferracane JL. Hygroscopic and hydrolytic effects in dental polymer networks. Dental Materials 2006;22(3):211-222. [PubMed: 16087225]

5. Wang Y, Spencer P, Hager C, Bohaty B. Comparison of interfacial characteristics of adhesive bonding to superficial versus deep dentin using SEM and staining techniques. J Dent 2006;34:26-34. [PubMed: 15907359]

6. Ito S, Saito T, Tay FR, Carvalho RM, Yoshiyama M, Pashley DH. Water content and apparent stiffness of non-caries versus caries-affected human dentin. J Biomed Mater Res B Appl Biomater 2005 Jan 15;72(1):109-116. [PubMed: 15389491]

7. Ito S, Hashimoto M, Wadgaonkar B, Svizero N, Carvalho RM, Yiu C, et al. Effect of resin hydrophilicity on water sorption and changes in modulus of elasticity. Biomaterials 2005;26:64496459. [PubMed: 15949841]

8. Sideridou I, Achilias DS, Spyroudi C, Karabela M. Water sorption characteristics of light-cured dental resins and composites based on Bis-EMA/PCDMA. Biomaterials 2004;25:367-376. [PubMed: 14585725]

9. Park J, Ye Q, Topp E, Spencer P. Enzyme-catalyzed hydrolysis of dentin adhesives containing a new urethane-based trimethacrylate monomer. J Biomed Mater Res Part B-Appl Biomater. 2009In press

10. Ye Q, Wang Y, Spencer P. Nanophase separation of polymers exposed to simulated bonding conditions. J Biomed Mater Res Part B: Appl Biomater 2009;88B:339-348. [PubMed: 18335432]

11. Kostoryz EL, Dharmala K, Ye Q, Wang Y, Huber J, Park J, et al. Enzymatic biodegradation of HEMA/ BisGMA adhesives formulated with different water. J Biomed Mater Res B Appl Biomater 2009;88B: 394-401. [PubMed: 18395826]

12. Park J, Ye Q, Topp EM, Kostoryz EL, Wang Y, Kieweg SL, et al. Preparation and properties of novel dentin adhesives with esterase resistance. J Appl Polym Sci 2008;107:3588-3597.

13. Santis AD, Baldi M. Photo-polymerization of composite resins measured by micro-Raman spectroscopy. Polymer 2004;45:3797-3804.

14. Park J, Ye Q, Topp EM, Lee CH, Kostoryz EL, Misra A, et al. Dynamic mechanical analysis and esterase degradation of dentin adhesives containing a branched methacrylate. J Biomed Mater Res Part B: Appl Biomater. 2009In Press

15. Zhang Y, Xu J. Effect of immersion in various media on the sorption, solubility, elution of unreacted monomers, and flexural properties of two model dental composite compositions. J Mater Sci: Mater Med 2008;19:2477-2483. [PubMed: 18253815] 
16. Podgorski M, Matynia T. Network structure/mechanical properties relationship in multimethacrylates-derivatives of nadic anhydride. J Appl Polym Sci 2008;109:2624-2635.

17. Yiu CKY, King NM, Pashley DH, Suh BI, Carvalho RM, Carrilho MRO, et al. Effect of resin hydrophilicity and water storage on resin strength. Biomaterials 2004;25:5789-5796. [PubMed: 15147825]

18. Lee SY, Huang HM, Lin CY, Shin YH. Leached components from dental composites in oral simulating fluids and the resultant composite strengths. Journal of Oral Rehabilitation 1998;25:575588. [PubMed: 9781860]

19. Ortengren U, Wellendorf H, Karlsson S, Ruyter IE. Water sorption and solubility of dental composites and identification of monomers released in aqueous environment. Journal of Oral Rehabilitation 2001;28:1106-1115. [PubMed: 11874509]

20. Sideridou I, Karabela M, Vouvoudi E. Dynamic thermomechanical properties and sorption characteristics of two commercial light cured dental resin composites. Dent Mater 2008;24:737-743. [PubMed: 17889316]

21. Mesquita RV, Geis-Gerstorfer J. Influence of temperature on the visco-elastic properties of direct and indirect dental composite resins. Dent Mater 2008;24:623-632. [PubMed: 17826827]

22. Kannurpatti AR, Anseth JW, Bowman CN. A study of the evolution of mechanical properties and structural heterogeneity of polymer networks formed by photopolymerizations of multifunctional (meth)acrylates. Polymer 1998;39(12):2507-2513.

23. Hill DJT, Perera MCS, Pomery PJ, Toh HK. Dynamic mechanical properties of networks prepared from siloxane modified divinyl benzene pre-polymers. Polymer 2000;41:9131-9137.

24. Lee K, Choi J, Lim B, Lee Y, Sakaguchi RL. Change of properties during storage of a UDMA/ TEGDMA dental resin. J Biomed Mater Res Part B: Appl Biomater 2004;68B:216-221. [PubMed: 14737771]

25. McCabe JF, Arikawa H. Rheological Properties of Elastomeric Impression Materials Before and During Setting. J Den Res 1998;77(11):1874-1880.

26. Shi S, Nie J. Investigation of 3,4-methylenedioxybenzene methoxyl methacrylate as coinitiator and comonomer for dental application. J Biomed Mater Res Part B-Appl Biomater 2007;82B:487-493. [PubMed: 17285604]

27. Charlesworth J. Effect of crosslink density on molecular relaxations in diepoxide-diamine network polymers. Part 2. The rubbery plateau region. Polymer Engineering \& Science 1988;28(4):230-236.

28. Sideridou I, Tserki V, Papanastasiou G. Study of water sorption, solubility and modulus of elasticity of light-cured dimethacrylate-based resins. Biomaterials 2003;24:655-665. [PubMed: 12437960] 

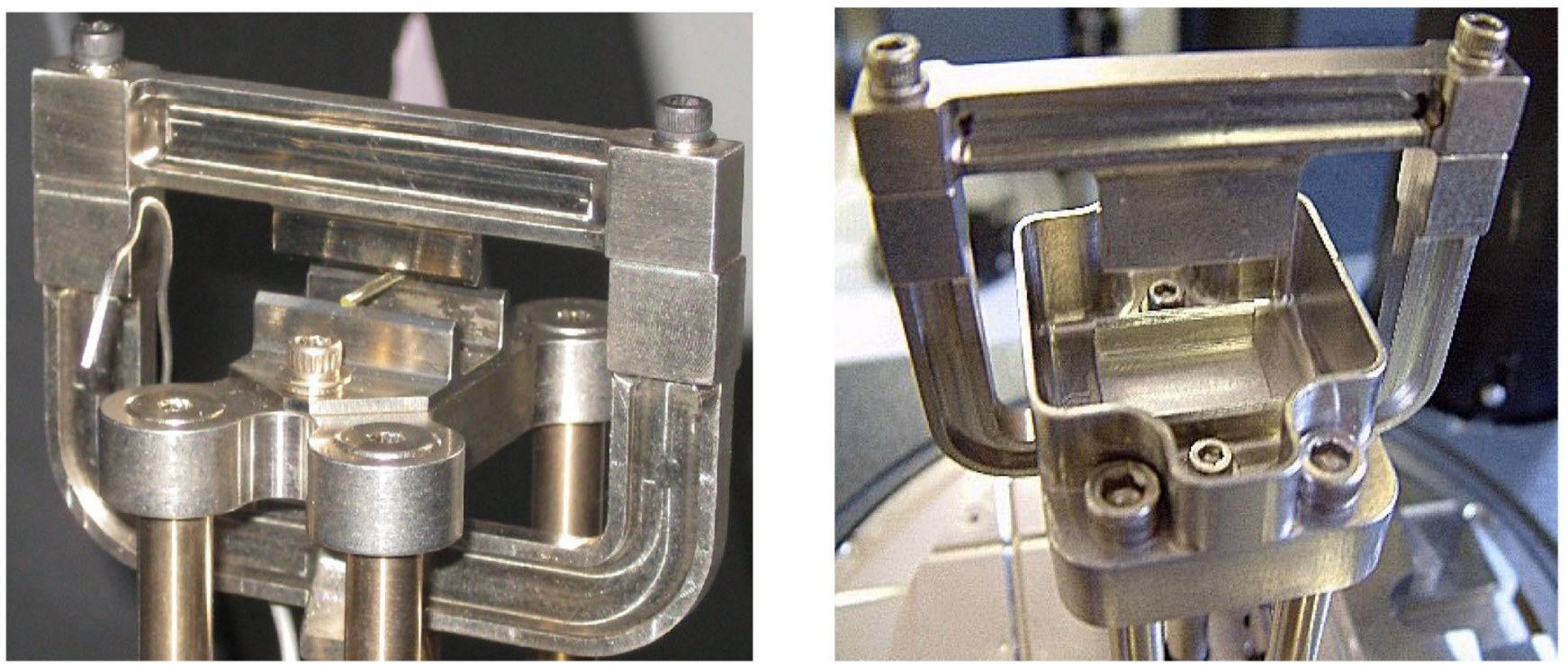

Fig. 1.

(a) Small standard 3-point bending clamp and (b) 3-point bending submersion clamp. 


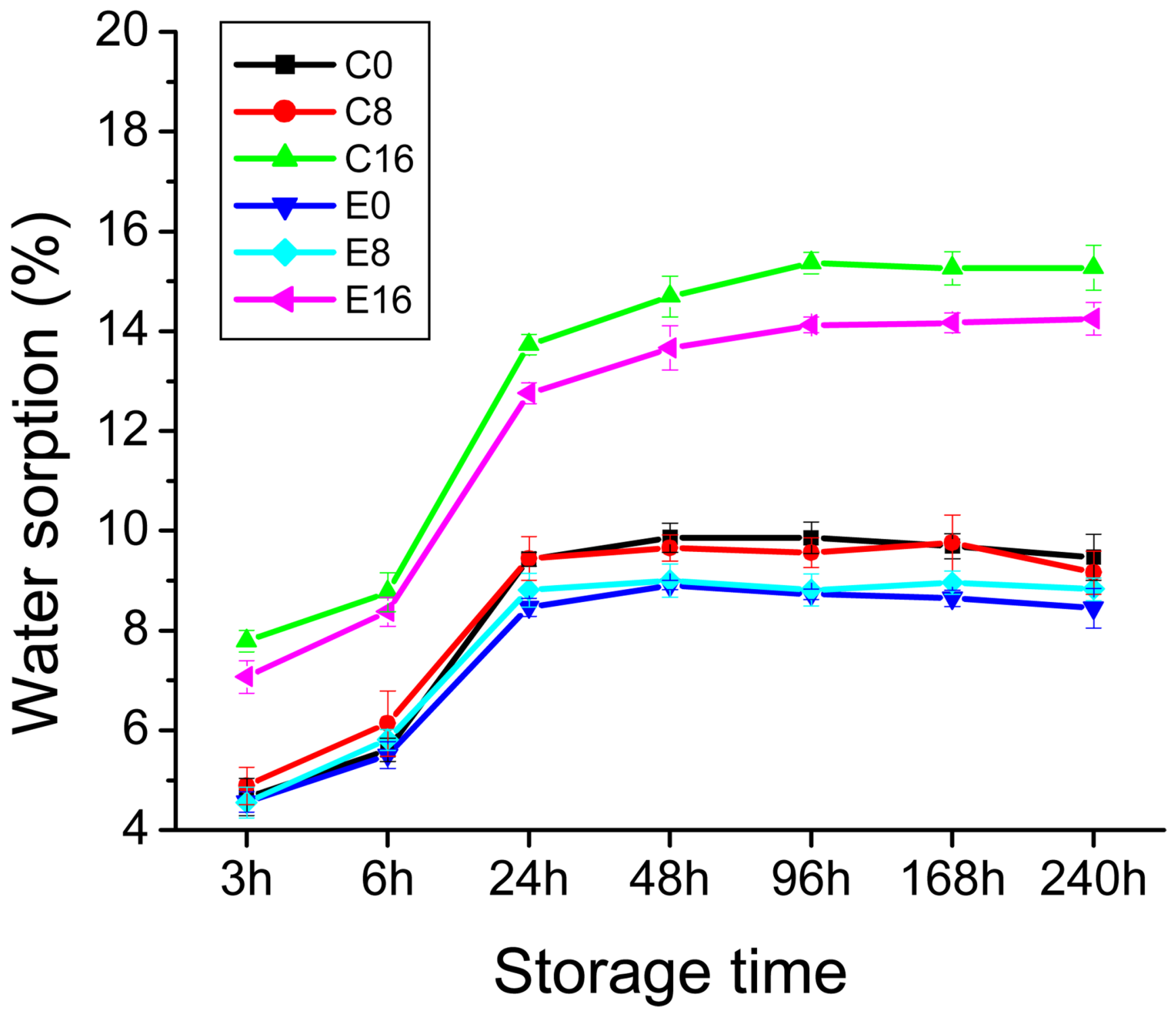

Fig. 2.

Water sorption of dentin adhesive polymers as a function of storage time. Four specimens were prepared for each adhesive polymer and immersed in distilled water at $37^{\circ} \mathrm{C}$ at fixed time intervals. Symbols: C0, C8, and C16, control formulations polymerized at $0 \%, 8 \%$, and $16 \%$ water; E0, E8, and E16, experimental formulations polymerized at $0 \%, 8 \%$, and $16 \%$ water. $\mathrm{n}$ $=4+/-$ S.D. 


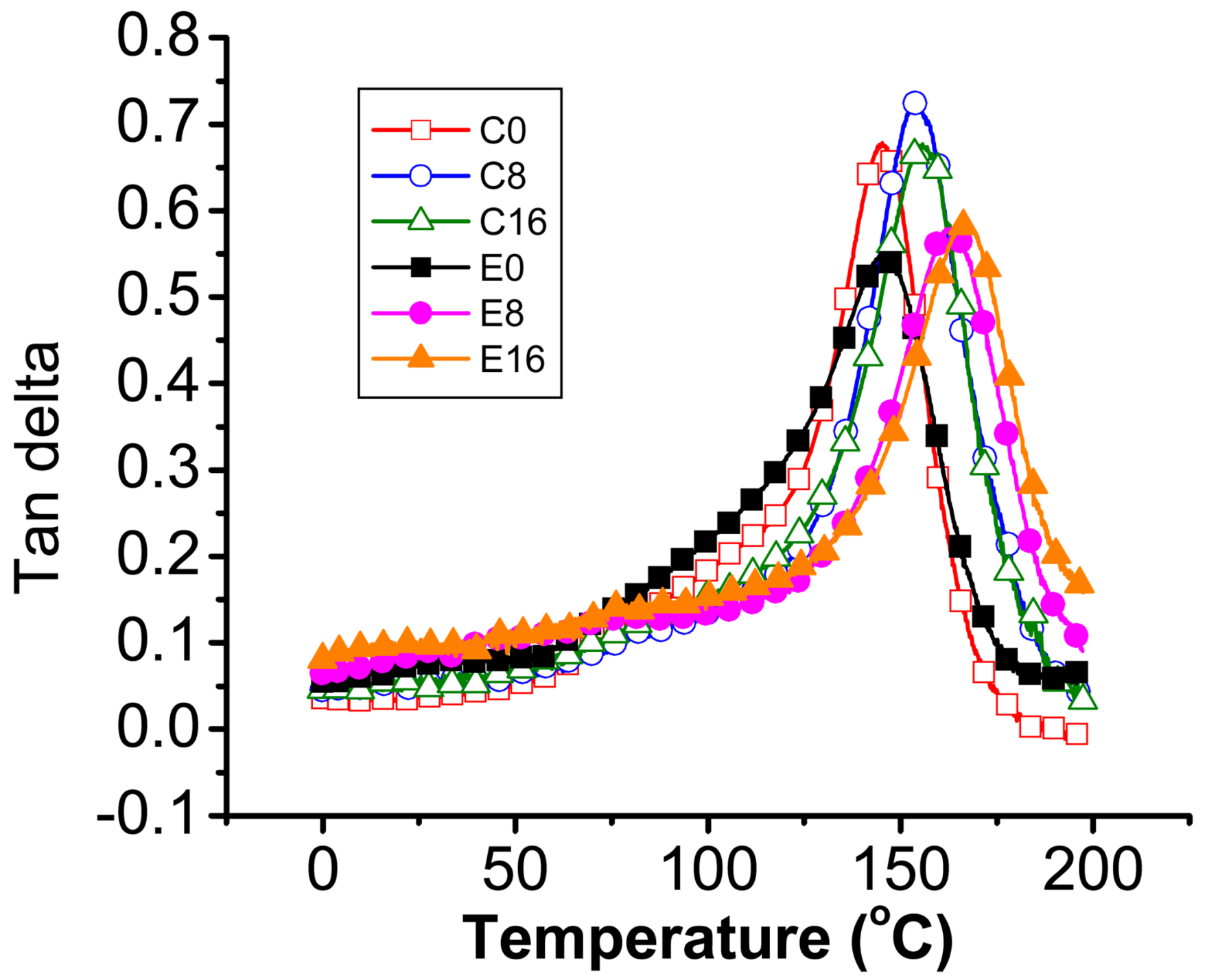

Fig. 3.

Representative tan delta versus temperature curves of control $(\mathrm{C} 0, \mathrm{C} 8, \mathrm{C} 16)$ and experimental (E0, E8, E16) adhesive polymers with $0 \%, 8 \%$ and $16 \%$ water contents. The polymerized samples were stored in the vacuum oven under drying agent at $37{ }^{\circ} \mathrm{C}$ for 1 week after curing. DMA (TA Instruments, Q800) with a three-point bending clamp was conducted over a temperature range of $0 \sim 200{ }^{\circ} \mathrm{C}$ with a ramping rate of $3{ }^{\circ} \mathrm{C} / \mathrm{min}$ at a frequency of $1 \mathrm{~Hz} . \mathrm{n}=$ $5+/$ S.D. 


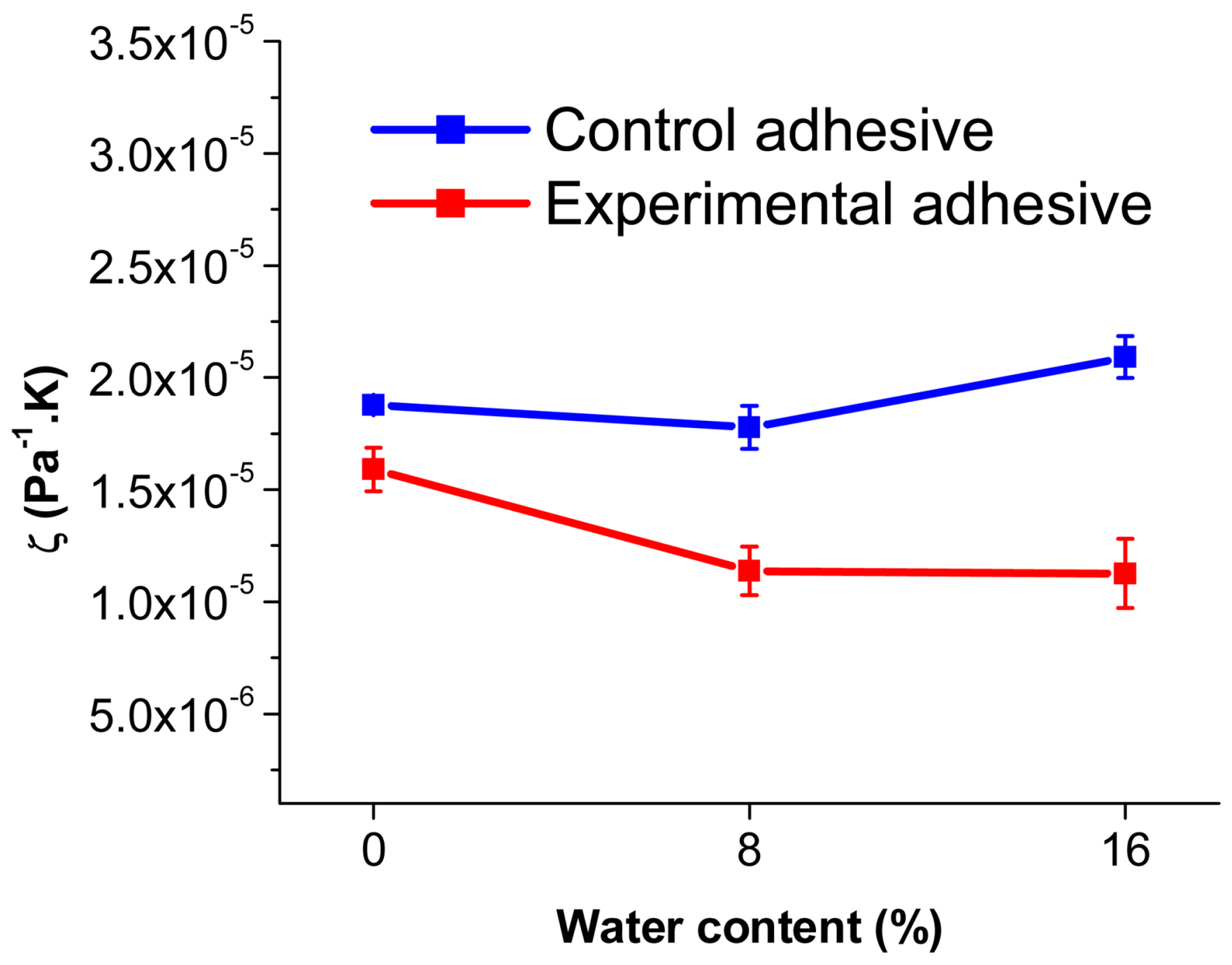

Fig. 4.

The inverse ratio of the modulus in the rubbery region to temperature at which the modulus was measured plotted as a function of water concentration(\%) in adhesive polymers. Value are mean (error bar : standard deviation) for $\mathrm{n}=5$ in each group. 
Park et al.

Page 13

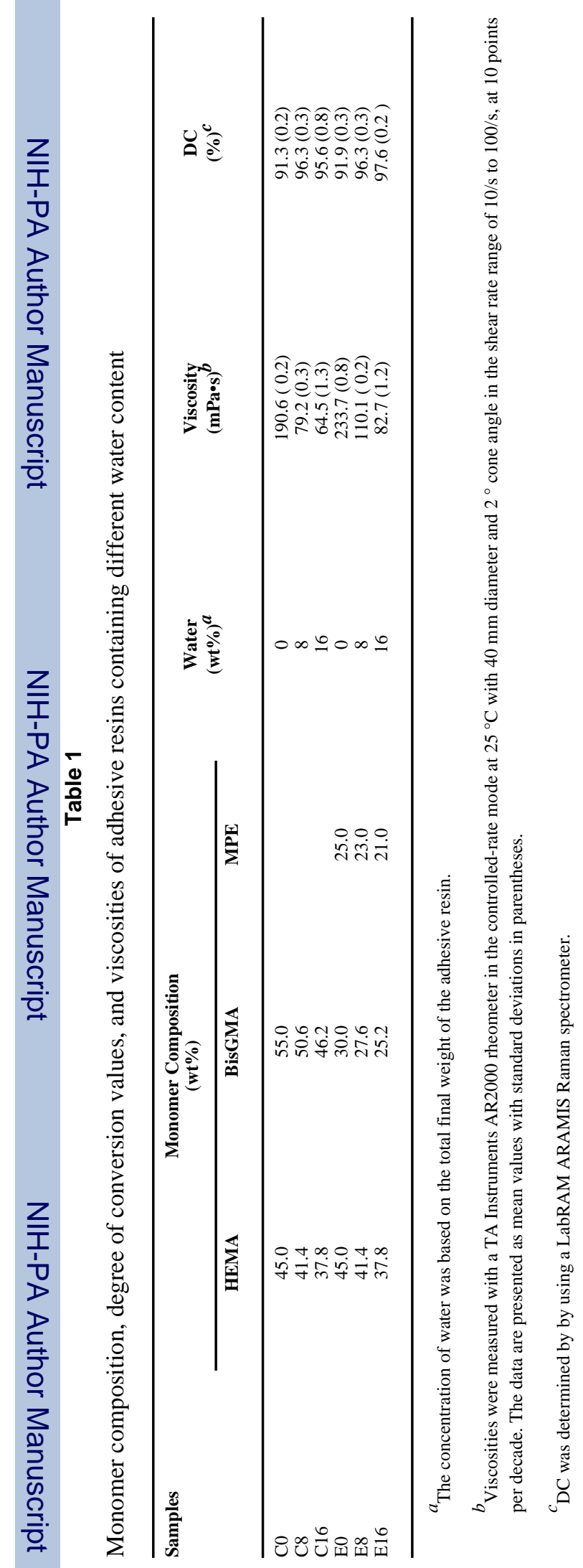

Dent Mater. Author manuscript; available in PMC 2010 December 1. 
Table 2

Mean values of water sorption, solubility and net water uptake of adhesive polymers

\begin{tabular}{lccc}
\hline & Water sorption (\%) & Solubility (\%) & Water Uptake (\%) $^{\boldsymbol{a}}$ \\
\hline C0 & $9.87(0.29)$ & $0.52(0.07)$ & 10.39 \\
C8 & $9.66(0.26)$ & $1.13(0.10)$ & 10.79 \\
C16 & $15.26(0.33)$ & $1.59(0.29)$ & 9.85 \\
E0 & $8.92(0.09)^{* *}$ & $0.46(0.14)$ & 10.11 \\
E8 & $9.01(0.33)^{* *}$ & $1.10(0.26)$ & 15.44 \\
E16 & $14.17(0.19)^{\#}$ & $1.27(0.22)$ & \\
\hline
\end{tabular}

Values are mean (S.D.) for $n=4$, percent change in weight.

${ }^{a}$ Water uptake is represented by the sum of water sorption and solubility.

* Significantly $(\mathrm{p}<0.05)$ different from control C0

** significantly $(\mathrm{p}<0.05)$ different from control $\mathrm{C} 8$

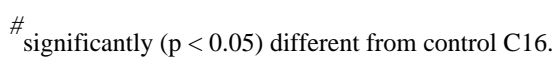


Table-3

Mean height and full-width-at-half-maximum values $\left({ }^{\circ} \mathrm{C}\right)$ of $\tan \delta$ peak of adhesive polymers

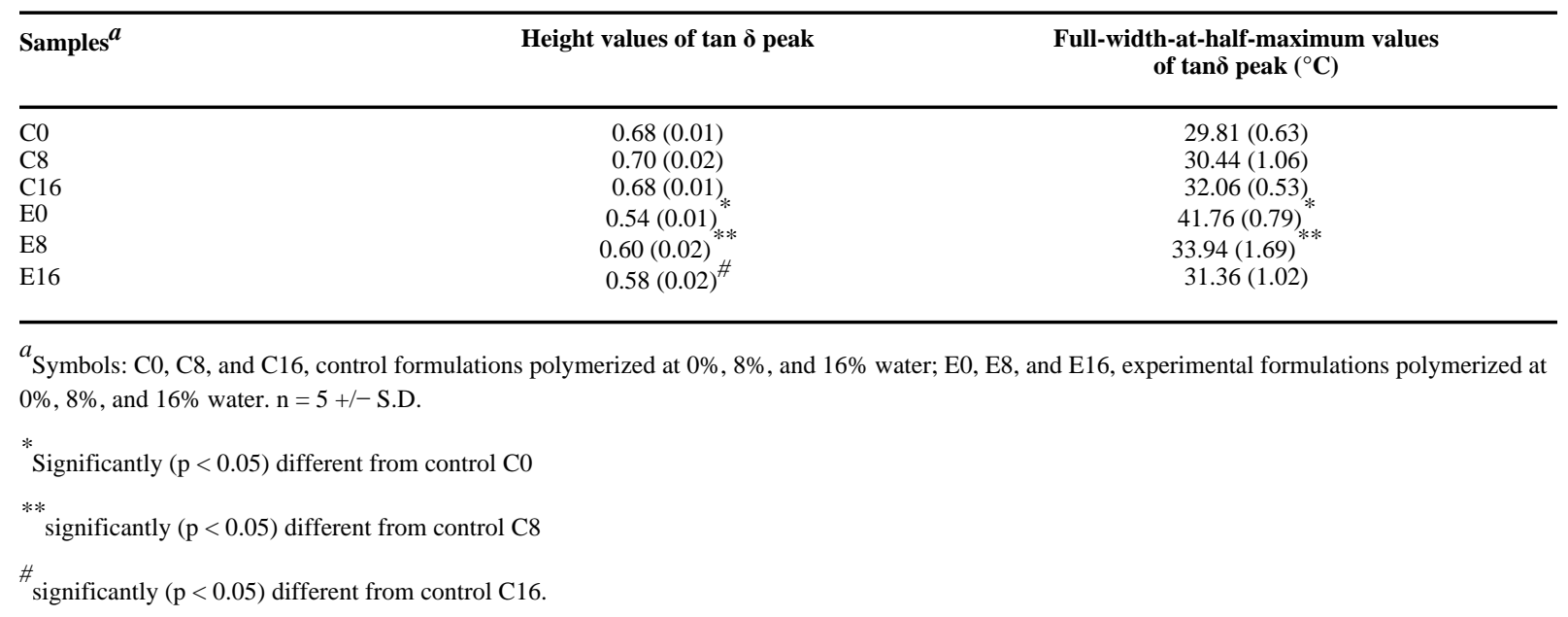


Table 4

Values of the storage modulus ( $\mathrm{E}^{\prime}$ ) of adhesive polymers for various temperatures

\begin{tabular}{|c|c|c|c|c|}
\hline \multicolumn{5}{|c|}{ Vacuum Dried Samples } \\
\hline \multirow[t]{2}{*}{ Samples } & \multicolumn{4}{|c|}{ Storage Modulus (MPa) } \\
\hline & $25^{\circ} \mathrm{C}$ & $37^{\circ} \mathrm{C}$ & $70^{\circ} \mathrm{C}$ & $\begin{array}{l}>175^{\circ} \mathrm{C} \\
\text { (rubbery region) }\end{array}$ \\
\hline $\begin{array}{l}\text { C0 } \\
\text { C8 } \\
\text { C16 } \\
\text { E0 } \\
\text { E8 } \\
\text { E16 }\end{array}$ & $\begin{array}{l}3600(104) \\
3300(65) \\
3100(102) \\
3700(222) \\
3600(69){ }^{* *} \\
3400(183)^{\#}\end{array}$ & $\begin{array}{l}3300(102) \\
3100(76) \\
2900(109) \\
3400(197) \\
3300(59)^{* *} \\
3200(178)\end{array}$ & $\begin{array}{l}2300(11) \\
2400(53) \\
2200(103) \\
2100(76) \\
2400(64) \\
2300(101)\end{array}$ & $\begin{array}{l}24.0(0.3) \\
25.4(1.3) \\
21.6(1.0) \\
28.5(1.9)^{*} \\
39.9(3.8)^{* *} \\
40.6(4.0)^{\#}\end{array}$ \\
\hline \multicolumn{5}{|c|}{ Water-submersed Samples } \\
\hline \multirow[t]{2}{*}{ 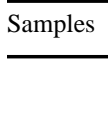 } & \multicolumn{4}{|c|}{ Storage Modulus (MPa) } \\
\hline & $25^{\circ} \mathrm{C}$ & $37^{\circ} \mathrm{C}$ & $70^{\circ} \mathrm{C}$ & $\begin{array}{l}>175^{\circ} \mathrm{C} \\
\text { (rubbery region) }\end{array}$ \\
\hline $\begin{array}{l}\text { C0 } \\
\text { C8 } \\
\text { C16 } \\
\text { E0 } \\
\text { E8 } \\
\text { E16 }\end{array}$ & $\begin{array}{l}2400(121) \\
2200(35) \\
2000(28) \\
2300(118) \\
2400(225) \\
2000(125)\end{array}$ & $\begin{array}{l}1900(100) \\
1800(46) \\
1700(30) \\
2000(111) \\
2100(197) \\
1700(116)\end{array}$ & $\begin{array}{l}261(46) \\
345(94) \\
454(70)^{*} \\
398(81)^{*} \\
800(73)^{* *} \\
730(50)^{\#}\end{array}$ & $\begin{array}{l}- \\
- \\
- \\
- \\
- \\
-\end{array}$ \\
\hline \multicolumn{5}{|c|}{$\begin{array}{l}\mathrm{n}=5+/-(\text { S.D. }) \\
* \text { Significantly }(\mathrm{p}<0.05) \text { different from control C0 }\end{array}$} \\
\hline \multicolumn{5}{|c|}{ ** significantly $(\mathrm{p}<0.05)$ different from control C8 } \\
\hline
\end{tabular}

